\title{
MODULAR TEST STAND FOR FATIGUE TESTING OF AERONAUTICAL STRUCTURES - VERIFICATION OF ASSUMPTIONS
}

\author{
Andrzej Leski ${ }^{1}$ • ORCID 0000-0003-3006-8877 \\ Wojciech Wronicz ${ }^{2 *}$ O ORCID 0000-0002-5580-1329 \\ Piotr Kowalczyk ${ }^{2}$ • ORCID 0000-0003-2947-3832 \\ Michał Szmidt ${ }^{2}$ ORCID 0000-0001-7995-594X \\ Robert Klewicki² • ORCID 0000-0002-1809-6632 \\ Karol Włodarczyk ${ }^{2}$, Grzegorz Uliński ${ }^{2}$
}
${ }^{1}$ Military University of Technology, Sylwestra Kaliskiego Str. 2, 00-908 Warsaw
${ }^{2}$ Łukasiewicz Research Network - Institute of Aviation, Krakowska Av. 110/114, 02-256, Warsaw
*wojciech.wronicz@ilot.lukasiewicz.gov.pl

\begin{abstract}
The Modular Test Stand was developed and manufactured to decrease the cost of fatigue testing and reduce the time of its completion as well as to enable testing specimens under more complex load conditions. The stand consists of three connected sections, similar to a wing box, all being loaded in the same way. Thanks to that, several specimens can be tested simultaneously. This configuration requires that stress and strain distribution should be reasonably uniform, as assumed in the design stage. The structure can be loaded with bending or torsion. A whole section, selected structural node or a specimen mounted in the structure as well as a repair or a sensor can be a test object.

Two stands, one for bending and one for torsion were prepared. This paper presents the verification of the assumed strain and stress distributions on the skin panels. The measurements were performed with the use of Digital Image Correlation (DIC) as well as strain gauges. DIC measurements were performed on one skin panel of the central section. Five strain gauge rosettes were installed on both panels of the one section. In addition, one rosette was applied to one skin panel in each of two other sections. Measurements were performed on the stand for torsion as well as on the stand for bending. The results of DIC analysis and strain gauge measurement during torsion show uniform shearing strain distributions on the panels. During bending, on the tensioned side, the strains obtained indicate quite uniform strain distributions. On the compressed side, local buckling of the skin panels results in high strain gradients. Strain levels obtained with the use of a DIC analysis and strain gauge measurements were similar. Moreover, horizontal displacements of markers in the spar axis during
\end{abstract}


bending was determined based on a series of photographic. The deflection line obtained in this way has a shape similar to arc, which is characteristic of the constant bending moment.

The stand was tested with torsional and bending loads in order to verify the design assumptions. The results of strain distributions on the skin panels with the use of DIC and strain gauges as well as the deflection line of the spar axis indicate that the Modular Test Stand performs as assumed and can be used for tests.

Keywords: Fatigue, Test, Airframe, Veryfication, Strain Gauge, DIC Article Category: Research Article

\section{INTRODUCTION}

Fatigue tests are especially important in aerospace since, in the case of a structural failure, the probability of a crash leading to loss of human life is very high. Moreover, to obtain best performances, a structure should be as light as possible. Mass limitations cause the occurrence of high (variable) stresses in many elements. Fatigue is also a major cause of failure in aerospace [1]. Fatigue tests are required in development of new as well as in modification of existing designs or extending service life [2]-[6]. Fatigue testing is also necessary in research works, where there is focusing on new structural technologies as well as in Non-Destructive Testing (NDT) and Structural Health Monitoring (SHM) systems [7]. Such SHM systems and NDT procedures are sometimes developed as part of aircraft maintenance programs [8].

Compared to static testing, fatigue testing is more complicated and time-consuming, and hence more expensive, too. For small or medium specimens fatigue tests can be performed on testing machines with loads usually restricted to tension (or tension and compression) only. In order to investigate larger structures or to introduce more complex loading conditions it is necessary to develop a dedicated stand, which is both expensive and time-consuming.

\section{MODULAR TEST STAND}

The authors have proposed a Modular Test Stand in order to enable fatigue testing at lower costs and in more complex load conditions [9], [10]. The following assumptions were adopted:

- the structure is similar to an airframe,

- the stand consists of three identical sections loaded in the same way during one experiment (several specimens can be tested at the same time),

- one section has dimensions of approximately 600x600x150 mm,

- a whole section, selected structural node or a specimen mounted in the structure as well as a repair or a sensor can be a test object,

- stress distribution on the panels during loading should be as uniform as possible (on both sides for torsion and on tensioned side for bending),

- exchange of the skin panel or whole section should be quite easy,

- the stand can be loaded with bending or torsion. 
A structure replicating a wing box, consisting of three identical sections was developed and manufactured. The single section comprises two spars and two ribs as well as two skins with stringers. The sections are connected to each other and to the fixings. Figure 1 presents the CAD model of this structure (wing box). Both skins in one section and the upper skins of the adjacent connections were hidden to show the internal construction.

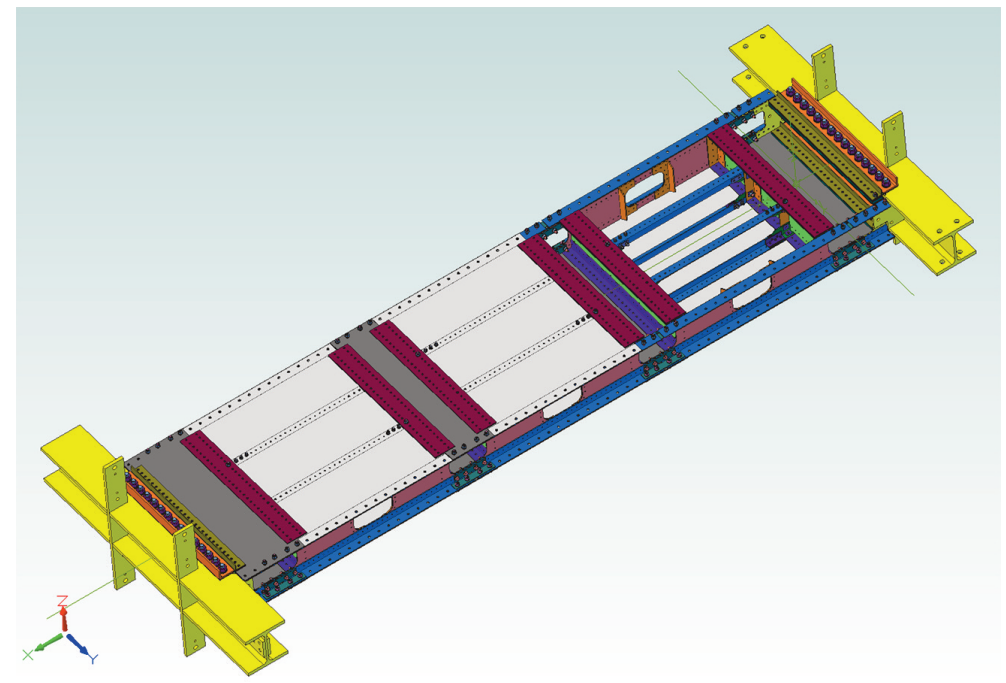

Fig. 1. Three connected sections with fixings.

The wing box with the fixings can be loaded with the bending or twisting moment. Because each section has to be loaded in the same way, the moment (bending or torsion) must be constant along the wing box length. Two stands, one for bending and one for torsion, were built. The transfer of the wing box from one stand to the other is quite simple. The stands are shown in Fig. 2.

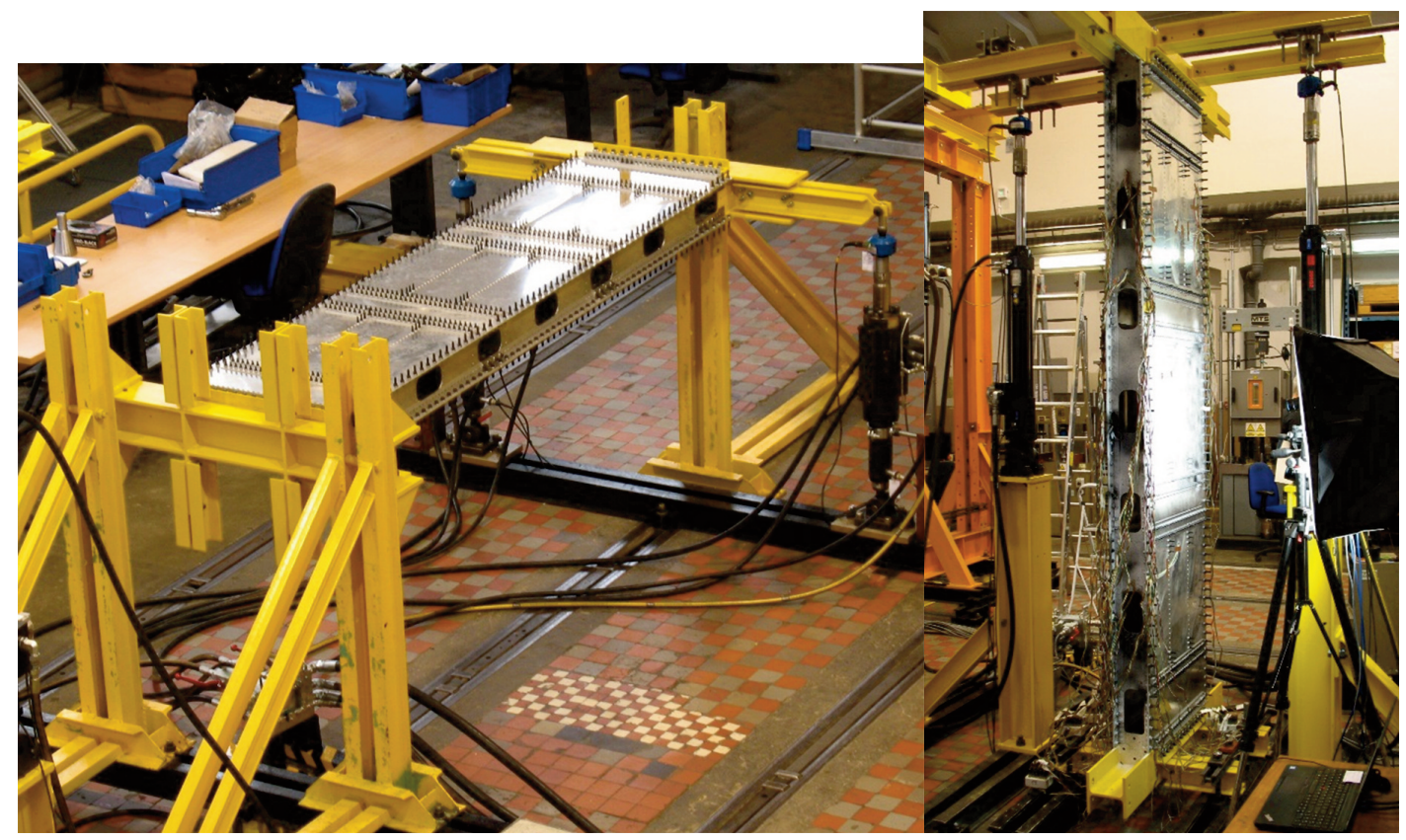

Fig. 2. Wing box on stand for torsion (left) and bending (right). 
On both stands, one end is fixed and the other is loaded by two hydraulic actuators generating moment. In the case of torsion, there is the additional support in the axis of rotation, which prevents potential bending (Fig. 3).

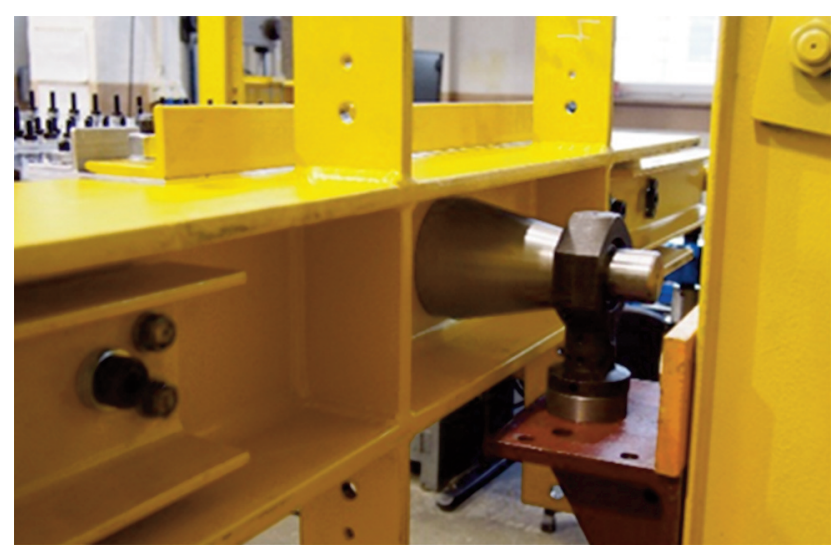

Fig. 3. Support in axis of rotation.
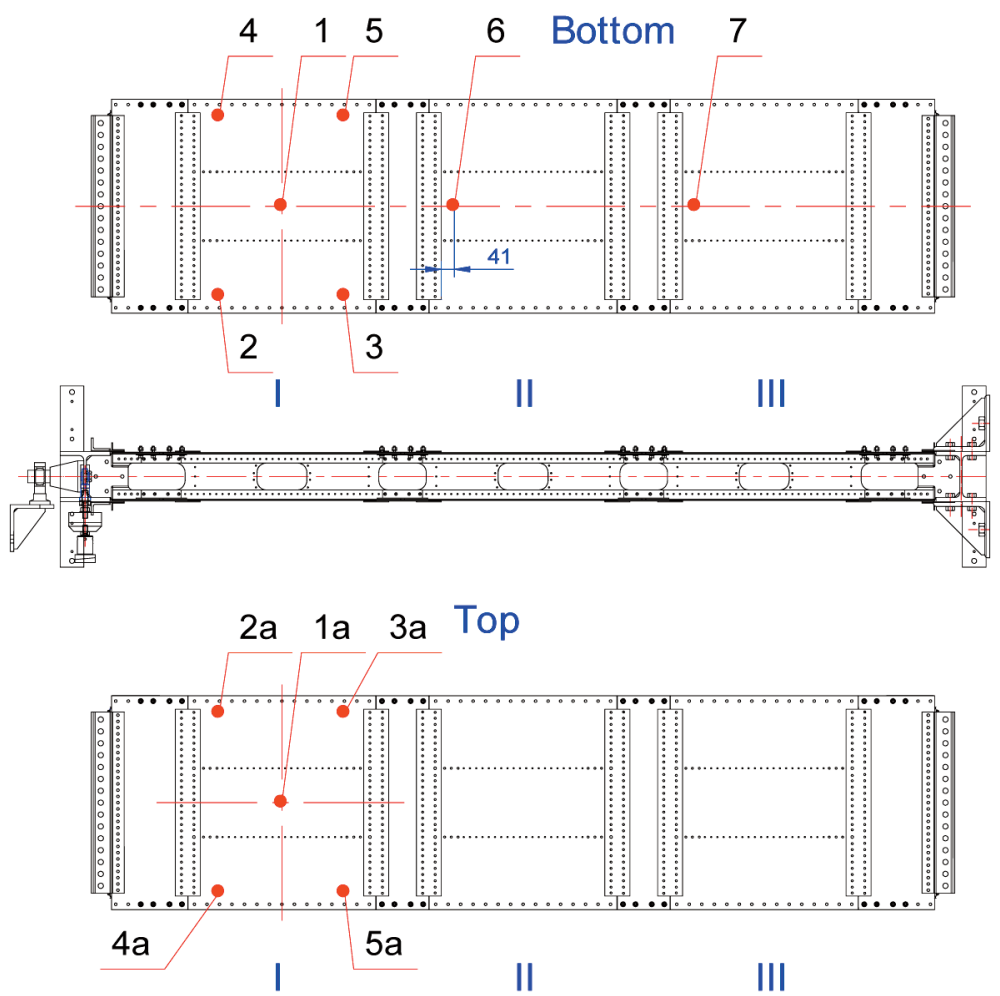

Fig. 4. Labels and location of strain gauge rosettes on skin panels.

After manufacturing and installation on the stand, it was crucial to verify if the structure performed as assumed and if it could be used for testing the specimens. The strain gauge rosettes were installed at selected points on the skin panels in order to verify the strain distribution and determine the load level in these elements. The location 
of these points is presented in Fig. 4. In the section I there are 5 rosettes on both sides, in the section II and III there is one rosette on one side. The orientation of the rosettes is shown in Fig. 5. In the centre of the panel (Rosettes 1 and 1a), the axis of Gauge 2 is parallel to the main wing box axis (' $x$ ' in Fig 5), the axes of Gauges 1 and 3 are at an angle of $45^{\circ}$ to the ' $x$ ' axis. Rosettes 6 and 7 on the section II and III have the same orientation. In the case of the rosettes at the panel's corners (2-5 and 2a-5a), axes of Gauges 1 are parallel to the ' $x$ ' axis while the axes of Gauges 3 are directed to the centre of the panel (see Fig. 5). Rosettes HBM 1-RY83-3/120 with $3 \mathrm{~mm}$ measuring grid length were used.
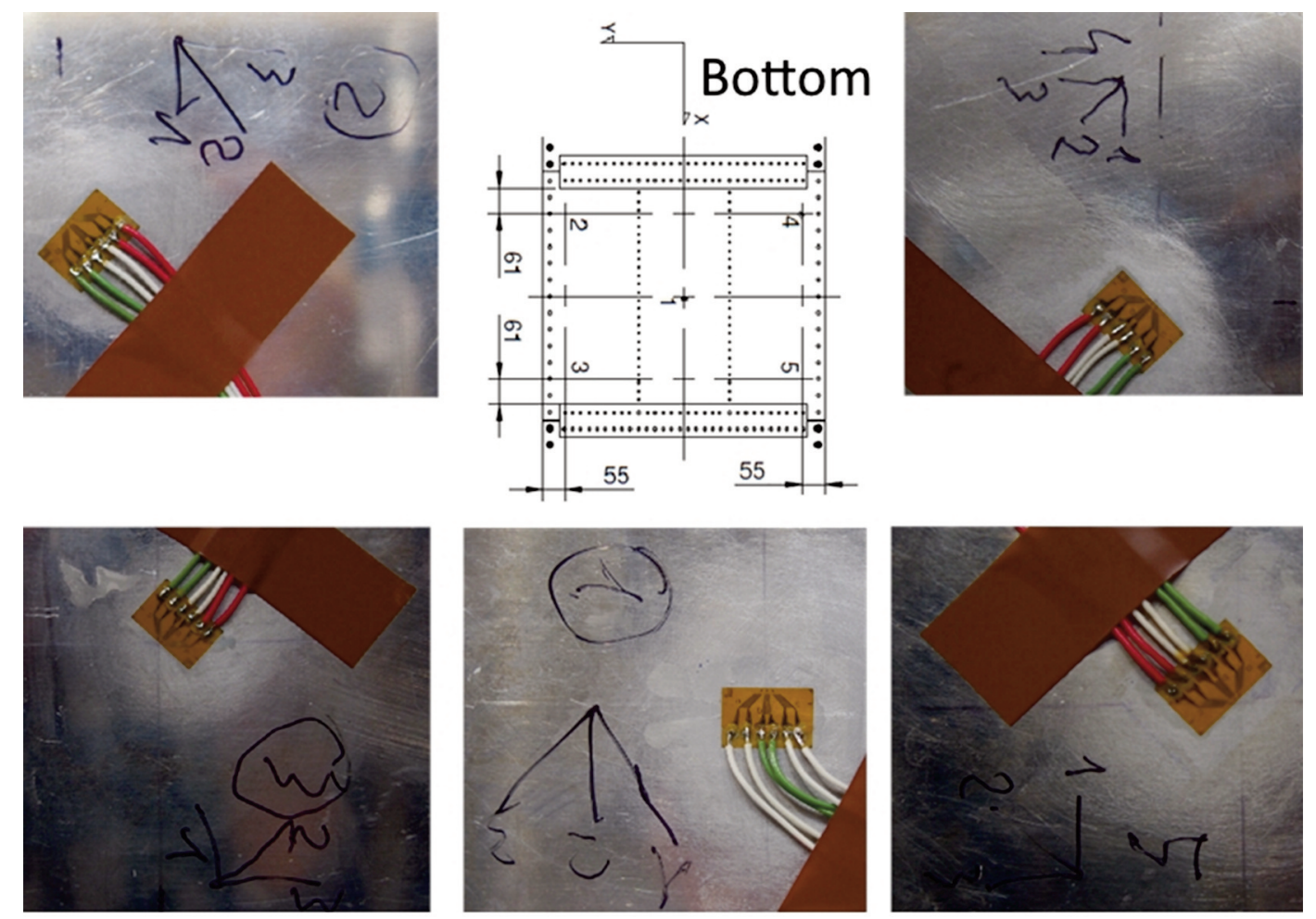

Fig. 5. Orientation of strain gauge rosettes on skin panel.

\section{STRAIN DISTRIBUTION DURING TORSION}

The wing box was loaded with a torsional moment equal to $9,1 \mathrm{kNm}$ in both directions. During loading, the strain distribution in the central part of the bottom skin panel in the middle section (II) was determined with the use of the 3D Digital Image Correlation (DIC) [11]. Figure 6. illustrates this measurement. Two Grasshopper $5 \mathrm{Mpx}$ (Pointgray) cameras with $25 \mathrm{~mm}$ focal lences were used. Strains were calculated with the GOM Correlate Professional 2018 software. The subset of 27 pixels and 17 pixels step were used. The areas with rivets were excluded from the analysis due to a high noise. 

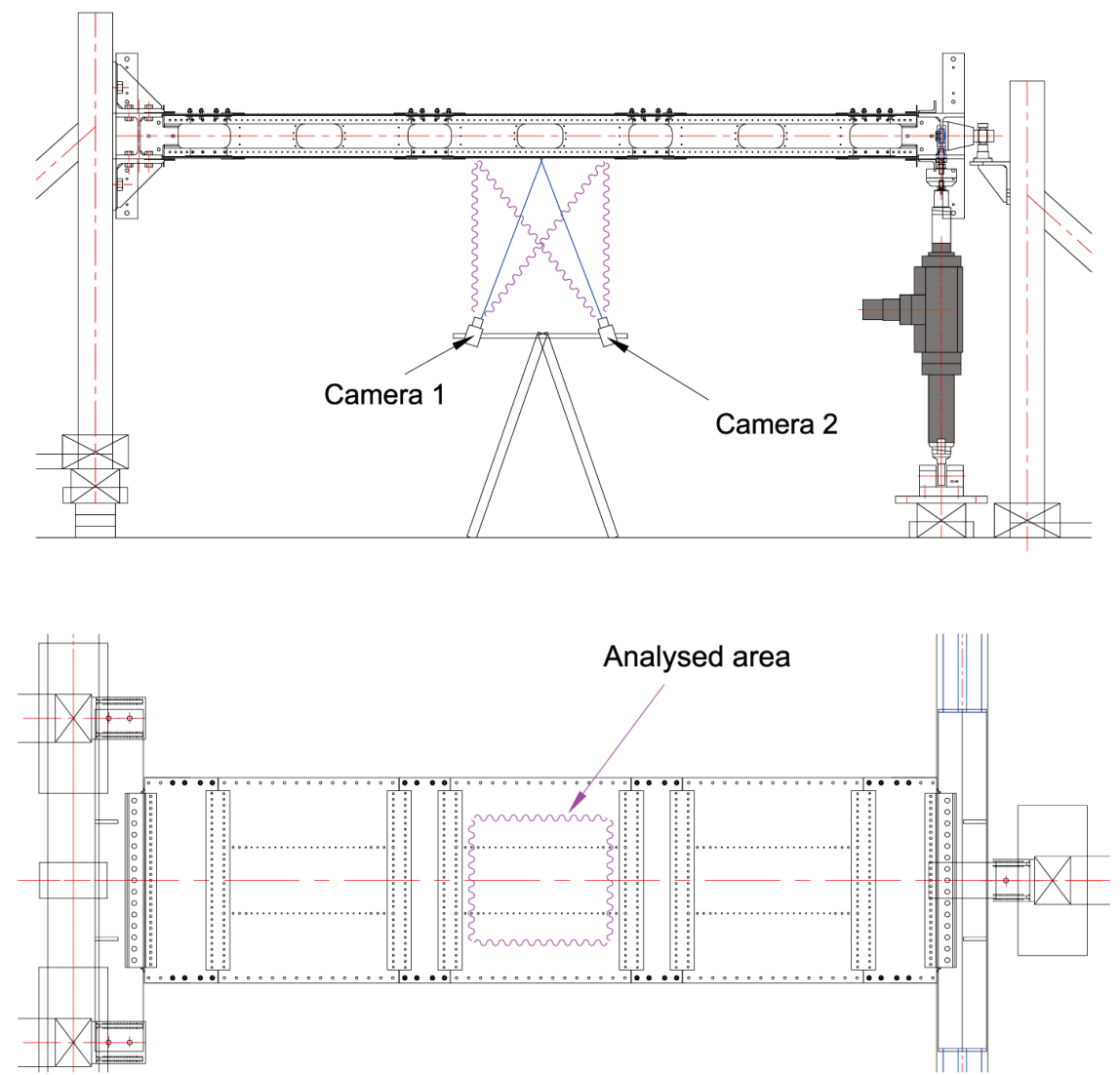

Fig. 6. DIC measurement during torsion.
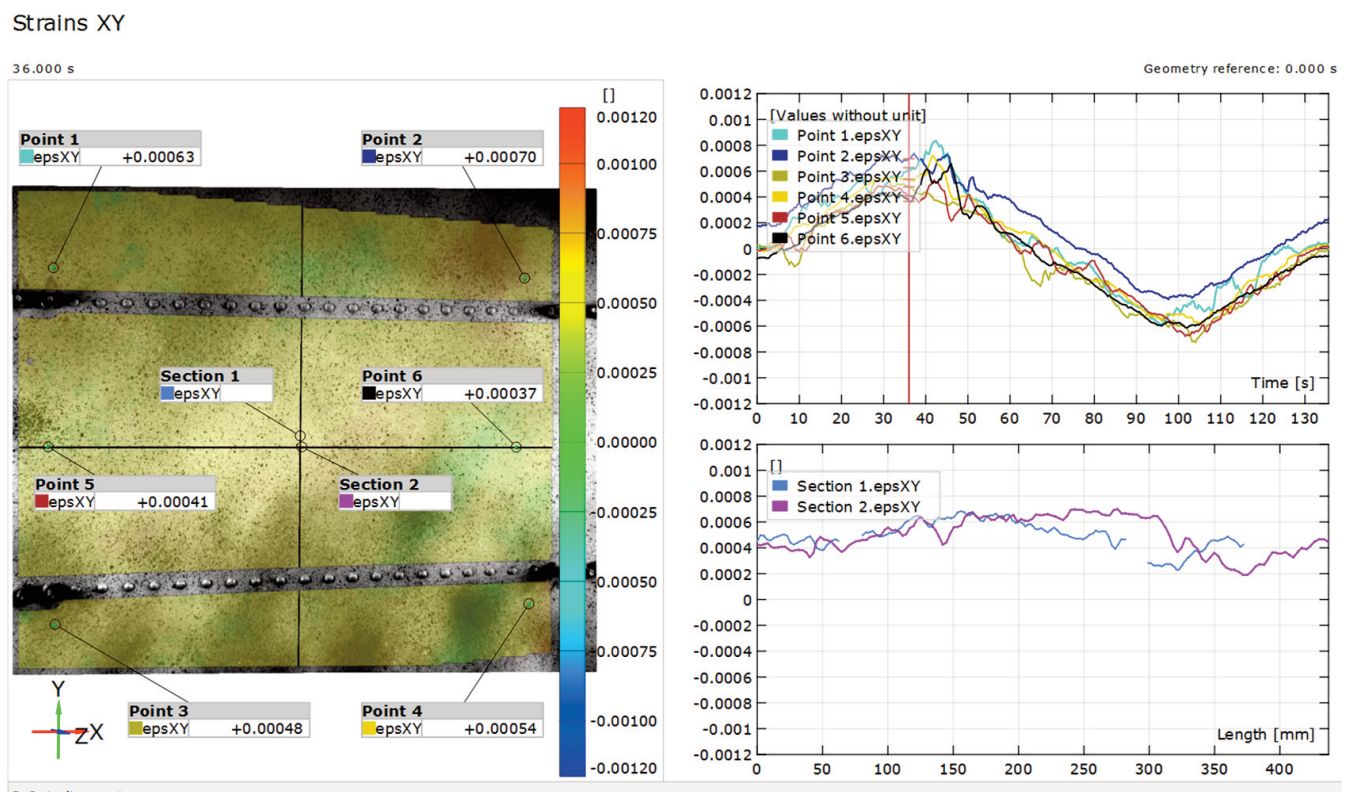

Fig. 7. $\varepsilon_{x y}$ strain distribution on skin panel at moment of first load extremum, left - map of strains, top - strain progress during test at selected points, bottom - strains distribution along lines. Points and lines (sections) marked in left picture. 
Fig. 7. and 8. present distribution of shearing strains $\varepsilon_{\mathrm{xy}}$ which represent the main strain component during torsion, in the analysed area for both load directions. The pictures show maps of the strain distribution (left) as well as graphs of the strain progress during the test at selected points (top) and strain distributions along lines (bottom) at moments of maximum loading. Selected points and lines (labelled as 'section 1' - vertical, and 'section 2'- horizontal) are marked in pictures on the left. Quite uniform shearing strain distributions were obtained, especially in the central part of the area analysed. Strains' level is about $\pm 0,0005-0006(500-600 \mu \mathrm{m} / \mathrm{m})$ in this region. The minimum absolute picked value of $\varepsilon_{\mathrm{xy}}$ strain in the whole analysed area is about 0,0002 while the maximum is about 0,0008 .
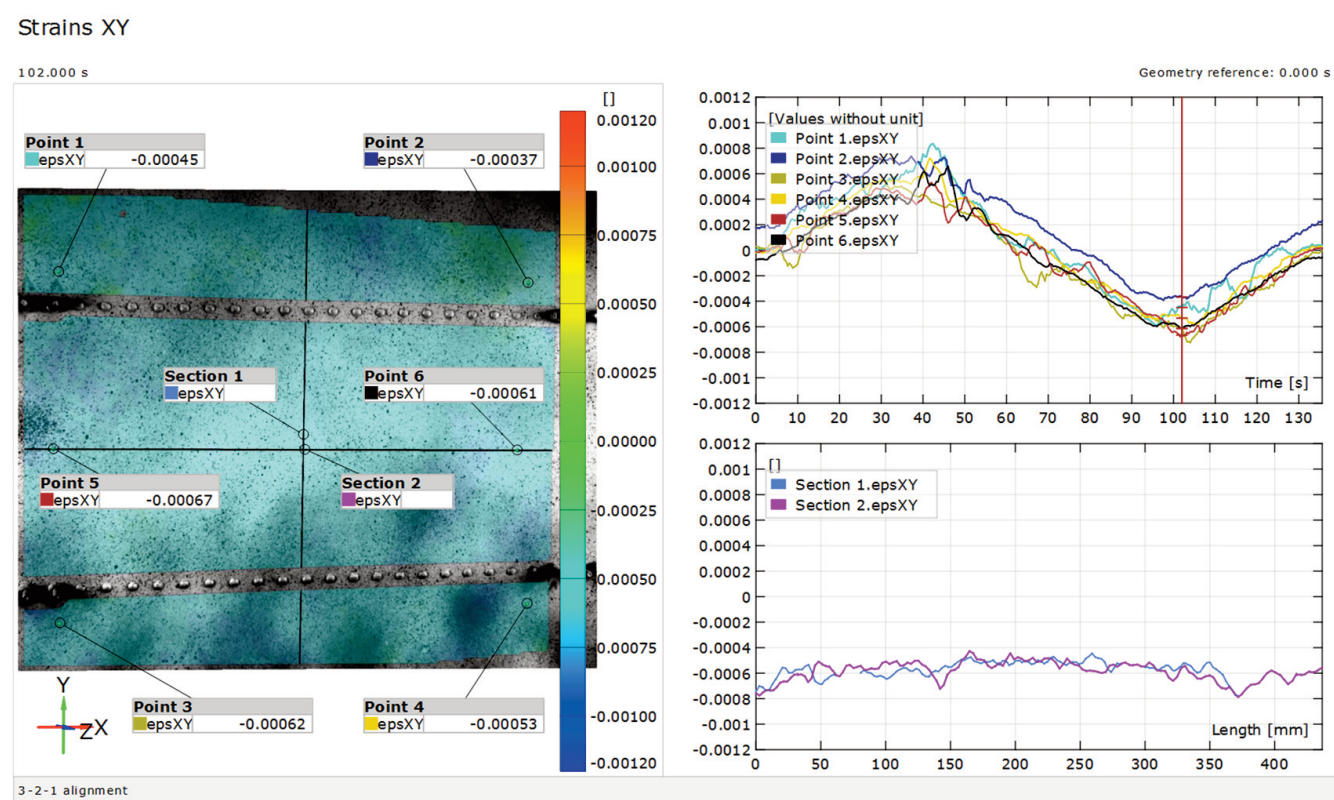

Fig. 8. $\varepsilon_{x y}$ strain distribution on skin panel in moment of second load extremum, left - map of strains, top - strain progress during test at selected points, bottom - strains distribution along lines. Points and lines (sections) marked in left picture.

After installation of the strain rosettes, during the next test with the same loading, strains measured by strain gauges were recorded. Fig. 9. presents shearing strains $\varepsilon_{\mathrm{xy}}\left(\varepsilon_{12}\right)$ calculated for the rosettes on the skin panels. In all locations except two (Rosette 2 and 3), shearing strains are similar, which confirms the uniform stress distribution in the skin panels during torsion. The higher shearing strain obtained for Rosette 2 was due to a higher strain recorded by Gauge 2-3 (Rosette 2, section 3, measuring strains perpendicular to the main wing box axis $\mathrm{x}$ (see. Fig. 5). In the case of Rosette 3, the lower shearing strain was due to a lower strain in Gauge 3-2 (Rosette 3 , section 2 , measuring strains at an angle of $45^{\circ}$ to the main wing box axis $\mathrm{x}$ ). The results obtained by the rest of the sections in these rosettes were similar to those obtained for the corresponding sections in other rosettes in the skin panels. These differences in the level of strains could have been caused by local buckling of the skin during torsion or the result of some malfunction during measurement. The values of shearing strains obtained in DIC and strain gauge measurements were similar. 


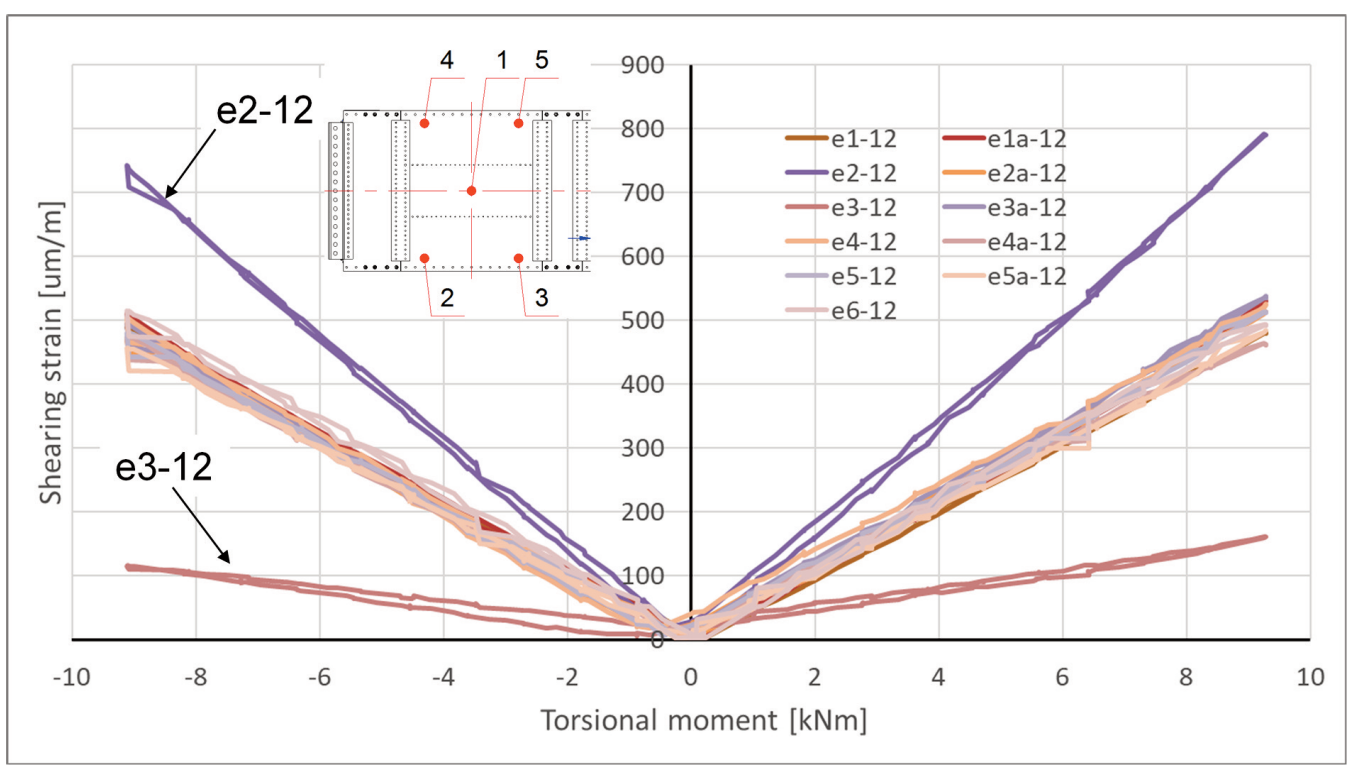

Fig. 9. Shearing strains $\varepsilon_{\mathrm{xy}}\left(\varepsilon_{12}\right)$ calculated for rosettes on skin panel.

\section{STRAIN DISTRIBUTION DURING BENDING}

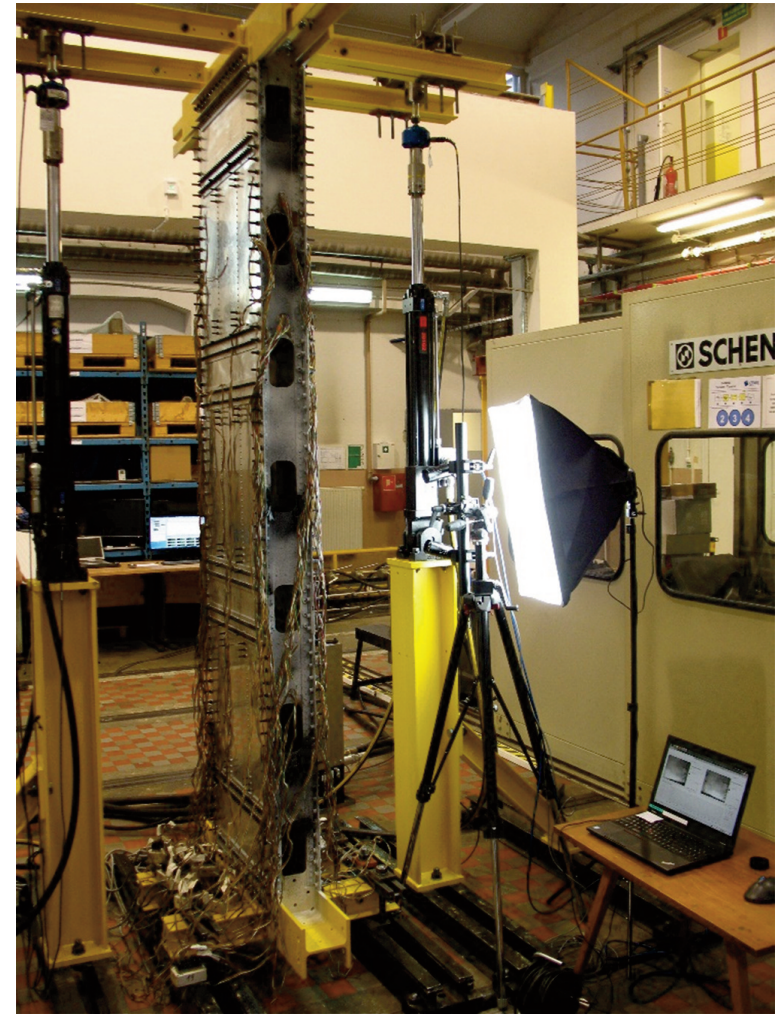

Fig. 10. Wing box on stand for bending prepared for DIC measurements.

In the next step, the wing box was installed in the bending stand and loaded successively in both directions with the bending moment equal to $18.1 \mathrm{kNm}$. Depending 
on the load direction, panels on a particular side were compressed or tensioned. The main strain component in the skins was tensile or compressive strain. The DIC system same as during torsion was used to determine strain distribution in a part of the middle panel. Cameras were installed one above the other. Fig. 10 presents the stand with the DIC system.
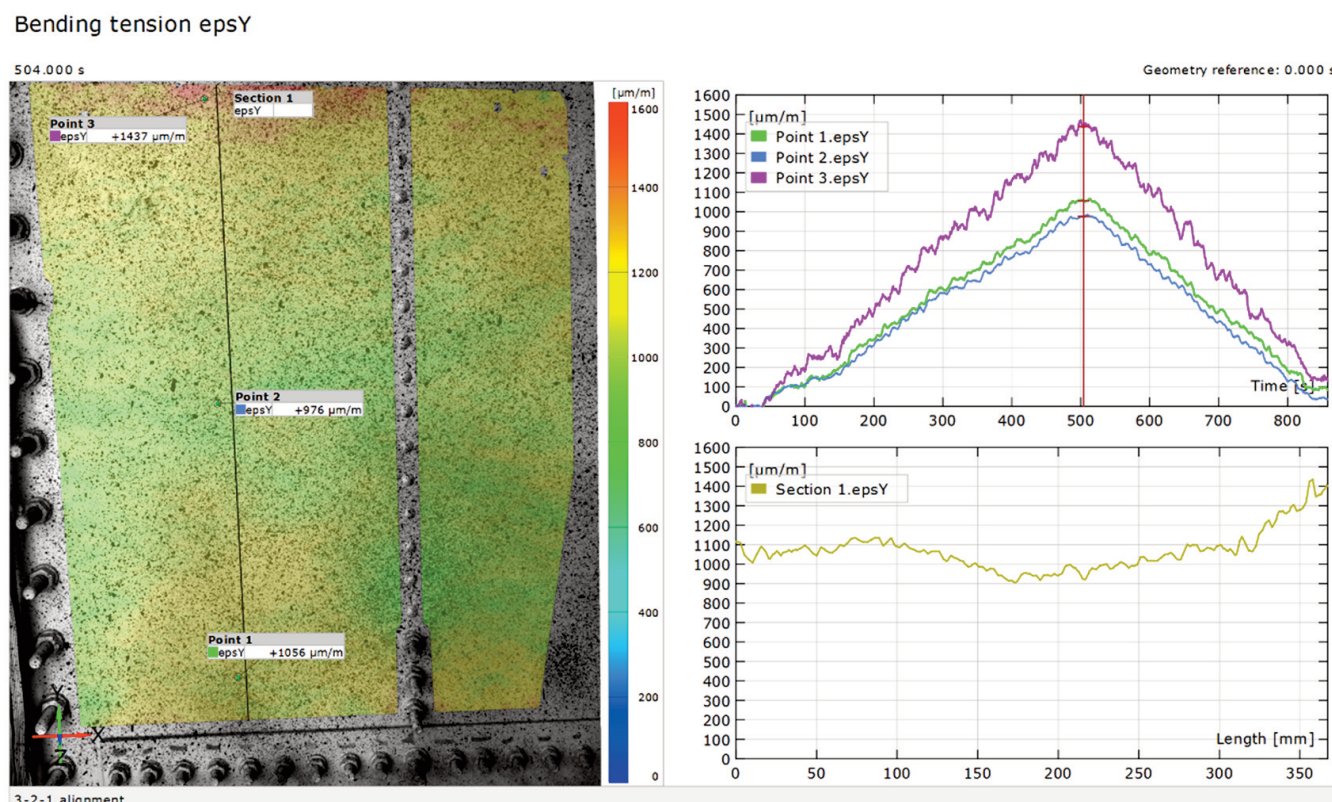

Fig. 11. $\varepsilon_{\mathrm{y}}$ strain distribution on the skin panel during bending (panel tensioned), left - map of strains, top - strain progress during test at selected points, bottom - strains distribution along the line. Points and line (section) marked in left picture.
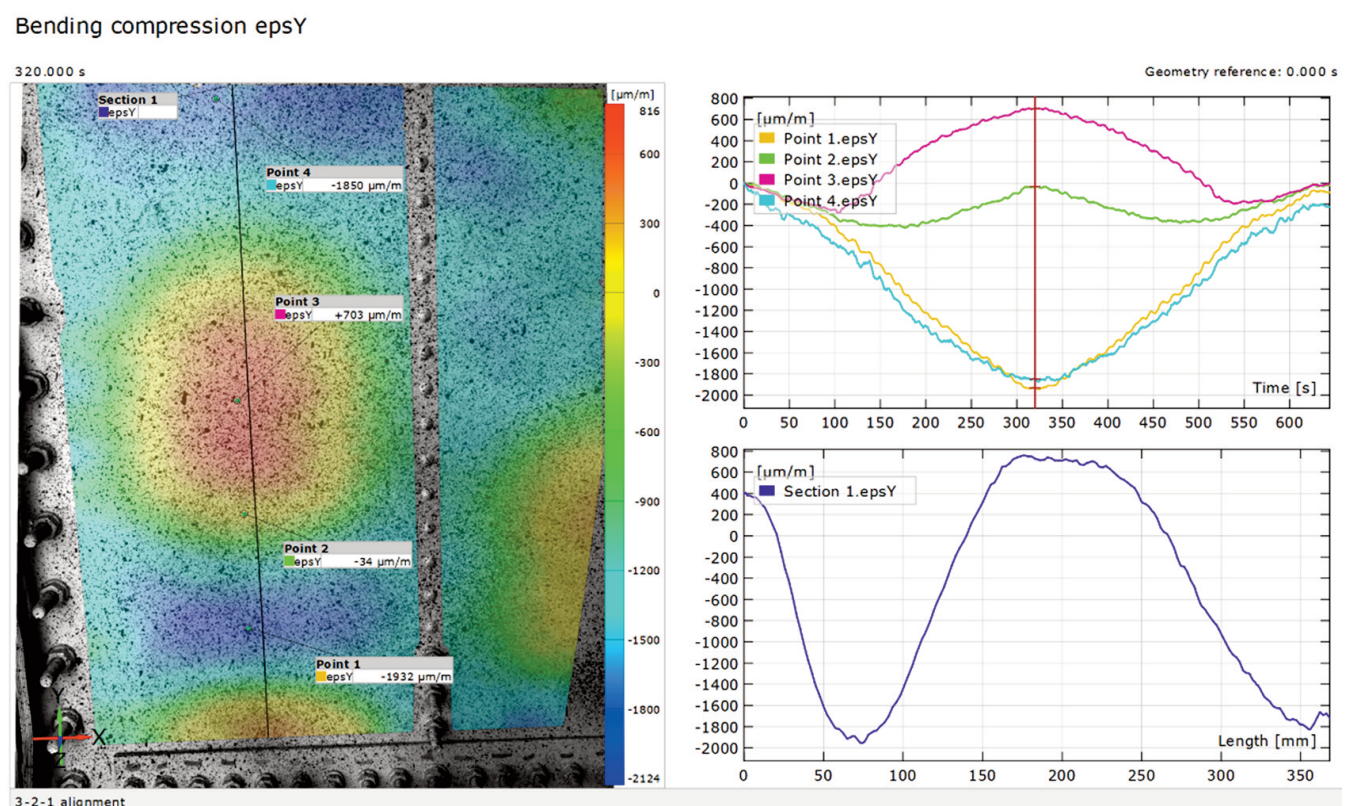

Fig. 12. $\varepsilon_{\mathrm{y}}$ strain distribution on skin panel during bending (panel compressed), left - map of strains, top - strain progress during test at selected points, bottom - strains distribution along the line. Points and line (section) marked in left picture. 
Fig. 11-12 show strain distribution of $\varepsilon_{\mathrm{y}}$ on the analysed area in the middle skin panel. The axes of the coordinate system used in the DIC analysis are marked at the bottom left corners of the pictures. The ' $y$ ' axis of the DIC coordinate system is parallel to the main ' $x$ ' axis of the wing box (vertical in Fig. 10-12 and horizontal in Fig. 6-8). This is the direction of tensile or compressive strains caused in the panels by bending. When the panel is tensioned (Fig. 11), quite uniform distribution of $\varepsilon_{\mathrm{y}}$ strain is visible. Strains' level is about $1000 \mu \mathrm{m} / \mathrm{m}$, but near the edge of the analysed area it increases to about $1400 \mu \mathrm{m} / \mathrm{m}$. During compression of the panel (Fig. 12), its local buckling results in a very non-uniform distribution of $\varepsilon_{\mathrm{y}}$ strain. The upper graph in Fig. 12 indicates that this phenomenon already starts at a low level of load, which results in high differences in strains values at various points.

Fig. 13 shows progress of $\varepsilon_{\mathrm{y}}$ strains recorded by the strain gauges during bending the structure in both directions. The coordinate system used in the DIC analyses was adopted (' $y$ ' axis parallel to the main wing box axis, vertical in Fig. 10-12). In the case of the positive bending moment, the panels with Rosettes 1a-5a were tensioned while the panels with Rosettes 1-7 were compressed (Fig.12). In the case of the negative bending moment, it was the reverse (Fig. 11). The curves in Fig. 13 are labelled with a rosette number and its section number. In the case of Rosettes 1, 1a and 6-7, parallel to the main wing box axis are Sections 2. In the case of other rosettes which are located in the panel's corners, the same direction has Sections 1. (see Fig. 4-5). Fig. 13 presents only the results of this rosettes sections. The uniform strain distribution and its linear progress is visible when panels are tensioned. $\varepsilon_{\mathrm{y}}$ strains reach value about $1000 \mu \mathrm{m} / \mathrm{m}$. Strain progresses during compression are nonlinear and vary significantly in terms of value, which is typical for local buckling. Maximum $\varepsilon_{\mathrm{y}}$ strain is higher than during tension and exceeds $1800 \mu \mathrm{m} / \mathrm{m}$. Values of $\varepsilon_{\mathrm{y}}$ strain obtained with the use of DIC and strain gauge measurement are similar.

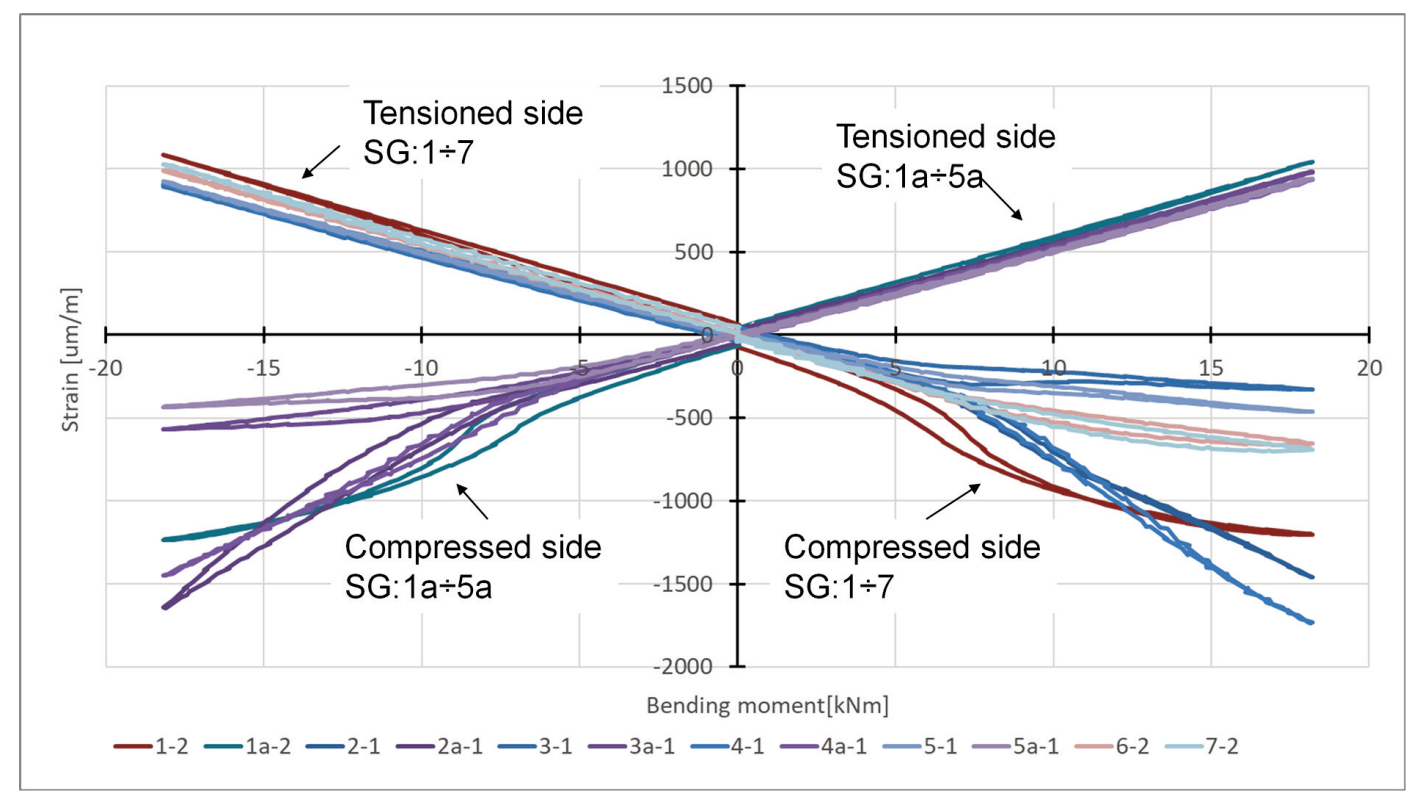

Fig. 13. $\varepsilon_{\mathrm{y}}$ strains on skin panels recorded by strain gauges during bending ('y' direction same as in fig. 11-12.). 


\section{DEFLECTION LINE OF SPAR AXIS DURING BENDING}

One of the fundamental assumptions adopted during development of the stand was that all sections should be loaded in the same way. This configuration of the designed stand resulted in the bending moment being constant along the wingspan. The same load condition was selected for the central part of the demonstrator in the TEBUK project [12] and in the ILX34 aircraft project [13]. The deflection line of a simple beam loaded with the constant bending moment is an arc because the constant bending moment results in the constant radius. The structure of the wing box is more complex but its shape under bending should be close to an arc. A 2D motion analysis of eight markers located in the spar axis was performed based on a series of photographs captured during the test. The camera was positioned perpendicular to the spar. Photos were scaled on the basis of the distance measured between selected points on the spar. The analysis of marker displacements was performed with the GOM Correlate software. Due to the relative accuracy of the displacements determined only the horizontal component was taken into account. Displacements obtained in the analysis are presented in Fig. 14.

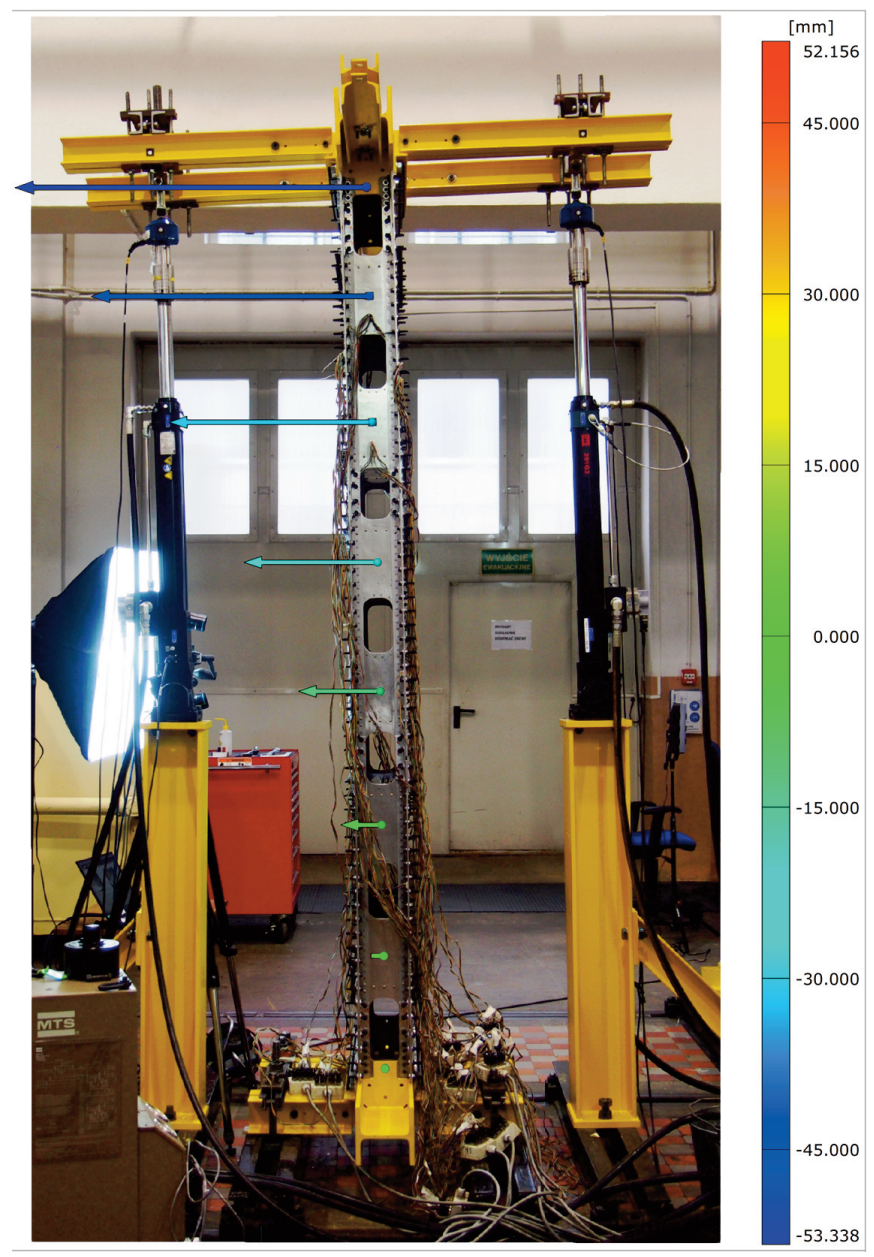

Fig. 14. Stand with horizontal displacements of markers on spar axis indicated by arrows. 
The arc equitation was found that reasonable well interpolates displacements determined in the analysis. It was assumed that the displacement of the first marker was zero and the radius of an arc was chosen to minimize the sum of squared differences. The comparison of displacements determined based on the photographs with this arc is shown in Fig. 15. The results confirm proper functioning of the stand.

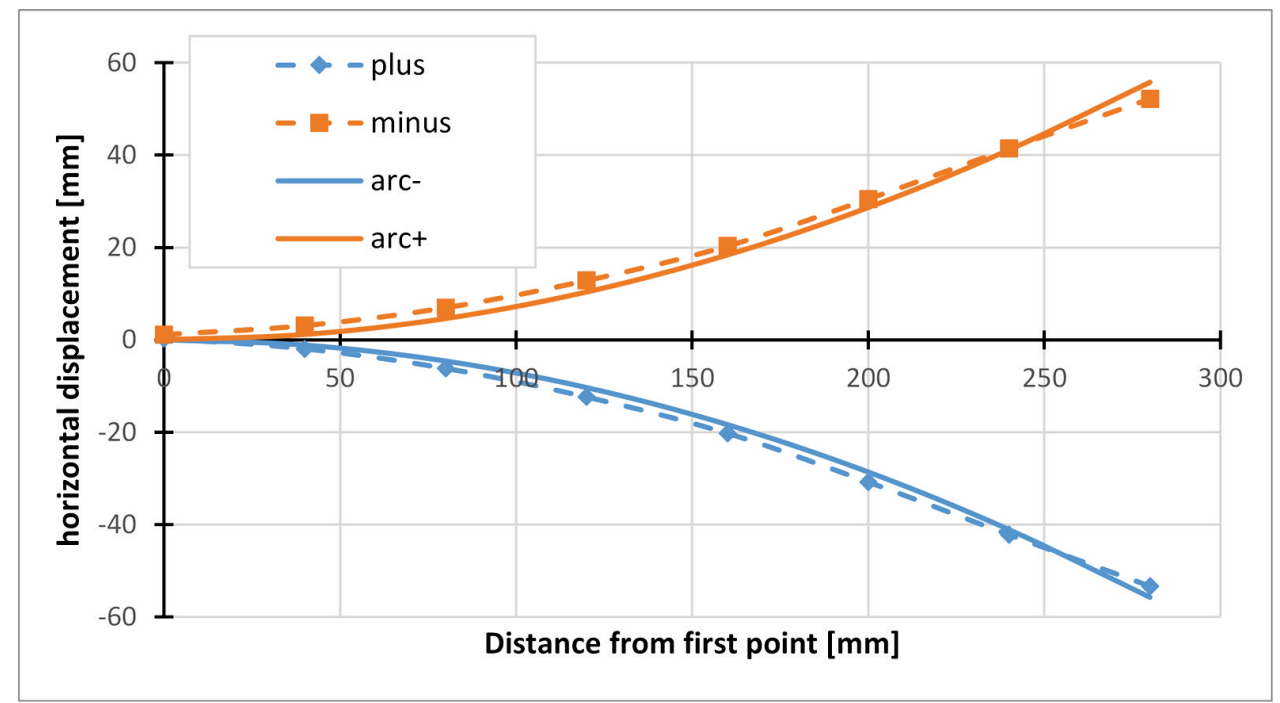

Fig. 15. Horizontal displacements of markers determined based on photographs compared with arc lines.

\section{CONCLUSIONS}

The Modular Test Stand was developed to decrease the cost of fatigue testing and reduce the time of its completion as well as to enable testing specimens under more complex load conditions. One of the fundamental assumption was the ability to test several specimens at the same time. Moreover, the stand can be used to test various types of objects including whole sections, structural nodes, skins, but also joints or repairs as well as various types of sensors. Therefore, it was assumed that a load (bending or twisting moment) should be constant along the wingspan while strain and stress distribution on the skin panels should be as uniform as possible. After manufacturing and installation on the stand, it was crucial to verify if the structure performed as assumed and whether it can be used for testing specimens.

The strain distribution on the skin panels during torsion and bending was determined with the use of strain gauges and Digital Image Correlation. The results obtained with these two methods were similar. During torsion, the measurements confirm uniform shearing strain distribution, especially in the central part of the skin, between the stringers. In the case of the rosettes, located in the corners of one panel, the strains levels were significantly different. Possibly, it was the result of local buckling of the panel or of some malfunction during the measurement. In the case of bending, the distribution of the strain parallel to the main axis of the wing box was very uniform when the panels were tensioned. On the side which was compressed, local buckling of the panels occured resulting in high differences in strains between various points of a single panel, as expected. 
In order to verify if the bending moment was constant along the wingspan, horizontal displacements of the marker located on the spar axis were determined based on the photographs of the spar. The shape of this deflection line was close to an arc indicating that the assumption of constant moment was true.

The results obtained during measurements show that the Modular Test Stand performs as assumed and can be used for tests.

\section{Acknowledgement}

The authors would like to thank the management of the Materials and Structures Research Centre and the Centre for Composite Technologies of the Lukasiewicz Research Network - Institute of Aviation for enabling this research.

The research was financed from the subsidy granted by the Polish Ministry of Science and Higher Education for statutory activities of the Institute of Aviation.

\section{REFERENCES}

[1] Findlay, S. J. and Harrison, N. D. (2002). Why aircraft fail. Materials Today, 5(11), pp. 18-25. https://doi.org/10.1016/S1369-7021(02)01138-0.

[2] Schijve, J. (2009). Fatigue damage in aircraft structures, not wanted, but tolerated?, International Journal of Fatigue, 31(6), pp. 998-1011. https://doi.org/10.1016/j.ijfatigue.2008.05.016.

[3] Ansell, H. (2015). Structural Integrity Assessment of Gripen NG Aircraft, in Proceedings 28th ICAF Symposium-Helsinki, Helsinki, pp. 610-624.

[4] Tsukigase, K., Fukuoka, T., Kumagai, K., Nakamura, T. and Taba, S. (2015). Curved Panel Fatigue Test for MRJ-200 Pressurized Cabin Structure, in Proceedings 28th ICAF Symposium-Helsinki, Helsinki, pp. 276-286.

[5] Leski, A., Kurdelski, M., Reymer, P., Dragan, K. and Sałaciński, M. (2015). Fatigue Life Assessment of PZL-130 Orlik Structure - Final Analysis and Results, in Proceedings 28th ICAF Symposium-Helsinki, Helsinki, pp. 294-303.

[6] Brzęczek, J., Gruszecki, H., Pieróg, L. and Pietruszka, J. (2014). Selected Aspects Related to Preparation of a Fatigue Test Plan of a Metallic Airframe. Fatigue of Aircraft Structures, 2014(6), pp. 88-94, https://doi.org/10.1515/fas-2014-0008.

[7] Rośkowicz, M. and Leszczyński, P. (2017). Evaluation of the Suitability of the Strain-Gauge Method for Measuring Deformations during the Fatigue Tests of Aviation Composite Structures. Fatigue of Aircraft Structures, 2017(9), pp. 7584. https://doi.org/10.1515/fas-2017-0006.

[8] Uchanin, V. (2020). Detection of the Fatigue Cracks Initiated near the Rivet Holes by Eddy Current Inspection Techniques, Transactions on Aerospace Research, 2(259), pp. 47-58. https://doi.org/10.2478/tar-2020-0010.

[9] Leski, A., Szmidt, M. and Wronicz, W. (2019). The modular test stand for fatigue testing of aeronautical structures - Design phase, AIP Conference Proceedings, 2078(1), p. 020021. https://doi.org/10.1063/1.5092024.

[10] Leski, A., Wronicz, W., Kowalczyk, P. and Szmidt, M. (2020). Conception of Modular Test Stand for Fatigue Testing of Aeronautical Structures. In: Niepokolczycki A., 
Komorowski J. (eds) ICAF 2019 - Structural Integrity in the Age of Additive Manufacturing. ICAF 2019. Lecture Notes in Mechanical Engineering. Springer, Cham. https://doi.org/10.1007/978-3-030-21503-3_59.

[11] Sutton, M. A., Orteu, J. J. and Schreier, H. (2009). Image correlation for shape, motion and deformation measurements: basic concepts, theory and applications. Springer Science \& Business Media.

[12]Bajurko, P. (2019). Modelling of the Aerospace Structure Demonstrator Subcomponent, Transactions on Aerospace Research, 1(254), pp. 37-52. https://doi.org/10.2478/tar-2019-0004.

[13] Łukasiewicz Research Network - Institute of Aviation. Completion of tests of the ILX-34 wing box demonstrator. Jul. 12, 2019.

From https://ilot.lukasiewicz.gov.pl/en/completion-of-tests-of-the-ilx-34-wing-boxdemonstrator/ 